\title{
Evidence-Based PET for Thoracic Tumours
}

\author{
Filippo Lococo, Alfredo Cesario, \\ Stefano Margaritora, and Giorgio Treglia
}

\subsection{Introduction}

Fluorine-18 fluorodeoxyglucose positron emission tomography/computed tomography $\left({ }^{18} \mathrm{~F}\right.$ FDG PET/CT) is a robust imaging tool that is currently used in daily clinical practice for the evaluation of thoracic malignancies. This chapter provides an overview of the current evidencebased data on the usefulness of PET/CT for the evaluation of patients with thoracic tumours including lung cancer, pleural and thymic tumours, and esophageal cancer.

F. Lococo $(\square) \cdot$ A. Cesario $\cdot$ S. Margaritora Department of General Thoracic Surgery, Catholic University of the Sacred Heart, Fondazione Policinico A. Gemelli, Rome, Italy

G. Treglia

Clinic of Nuclear Medicine and Molecular Imaging, Imaging Institute of Southern Switzerland, Ente Ospedaliero Cantonale,

Bellinzona and Lugano, Switzerland

Department of Nuclear Medicine and Molecular Imaging, Lausanne University Hospital and University of Lausanne, Lausanne, Switzerland

Health Technology Assessment Unit, Academic Education, Research and Innovation Area, Ente Ospedaliero Cantonale, Bellinzona, Switzerland e-mail: giorgio.treglia@eoc.ch

\subsection{Evidence-Based Data on PET in Primary Lung Tumours}

Herein we reviewed recent evidence-based data on the usefulness of ${ }^{18} \mathrm{~F}-\mathrm{FDG}$ PET/CT for: (1) characterization of solitary pulmonary nodules (SPNs), (2) non-small cell lung cancer (NSCLC) staging, (3) restaging after induction therapy and systemic therapy response assessment in NSCLC, (4) radiation therapy planning, (5) diagnosis of lung cancer recurrence in NSCLC, (6) prognostic evaluation, (7) management of small cell lung cancer (SCLC).

\subsubsection{Characterization of Solitary Pulmonary Nodules (SPNs)}

Characterizing a SPN detected incidentally or, as is the case more recently, on CT screening for lung cancer is a major public health issue. ${ }^{18} \mathrm{~F}$ FDG PET/CT is not indicated for characterization of SPNs of less than $8 \mathrm{~mm}$ in diameter according to current guidelines [1]. This threshold was set to take into account the spatial resolution of PET systems, due to the significant risk of false-negative findings for small lesions. However, over the last decade, the spatial resolution of ${ }^{18} \mathrm{~F}-\mathrm{FDG}$ PET/CT has significantly increased and future analysis could verify if this threshold will be modified accordingly. 


\subsubsection{Single-Time-Point ${ }^{18}$ F-FDG PET or PET/CT}

In the last decade, a robust evidence has been produced on the potential use of ${ }^{18} \mathrm{~F}$-FDG PET/ CT in early diagnosis of lung cancer (Table 5.1). Chien and colleagues [2] in 2013 conducted a systematic review on this topic reporting evidence of lung cancer screening programmes with ${ }^{18} \mathrm{~F}-\mathrm{FDG}$ PET, in which the estimated pooled sensitivity and specificity were $83 \%$ and $91 \%$, respectively. At that moment, despite PET appeared to have high sensitivity and specificity as a selective screening modality, the role of primary PET screening for lung cancer remained unknown and still undefined.

Subsequently, a further systemic analysis [3] reported a very high $(98.7 \%)$ pooled sensitivity of ${ }^{18} \mathrm{~F}$-FDG PET/CT in this setting while specificity was suboptimal (58.2\%).

In 2016, the research team headed by Madsen [4] suggested that ${ }^{18} \mathrm{~F}-\mathrm{FDG}$ PET/CT can rule out malignancy in most SPNs due to high sensitivity (recommendation level A) but at the same time the sensitivity of ${ }^{18} \mathrm{~F}-\mathrm{FDG} \mathrm{PET} / \mathrm{CT}$ in general is insufficient to rule out mediastinal lymph node metastasis (recommendation level A). Therefore, with few exceptions (lesions $<1 \mathrm{~cm}$ and non-solid lesions), they concluded that SPNs could be presumptively considered benign if ${ }^{18} \mathrm{~F}$-FDG PET is negative. In addition, lymph node metastasis in the mediastinum cannot be ruled out on the basis of a negative ${ }^{18} \mathrm{~F}-\mathrm{FDG}$ PET/CT, and confirmative (mini)invasive staging should be performed in most patients.

More recently, a further meta-analysis [5] showed that the pooled sensitivity and specificity of ${ }^{18} \mathrm{~F}-\mathrm{FDG}$ PET/CT in characterizing SPNs were $82 \%$ and $81 \%$, respectively, demonstrating moderate accuracy for ${ }^{18} \mathrm{~F}$-FDG PET/CT in differentiating malignant from benign SPNs.

A further meta-analysis exploring the value of ${ }^{18} \mathrm{~F}-\mathrm{FDG}$ PET/CT in the diagnosis of SPNs was reported in 2018 [6]. Pooled results indicated a sensitivity of $89 \%$ and a specificity of $70 \%$.

Table 5.1 Main findings of included meta-analyses on the diagnostic performance of PET or PET/CT with different tracers in patients with solitary pulmonary nodules

\begin{tabular}{|c|c|c|c|c|c|c|}
\hline Indication & Tracer & Authors & Year & $\begin{array}{l}\text { Patients } \\
\text { included }\end{array}$ & $\begin{array}{l}\text { Pooled sensitivity } \\
(95 \% \mathrm{CI})\end{array}$ & $\begin{array}{l}\text { Pooled } \\
\text { specificity } \\
(95 \% \mathrm{CI})\end{array}$ \\
\hline \multirow[t]{12}{*}{$\begin{array}{l}\text { Evaluation of suspicious } \\
\text { primary lung tumour }\end{array}$} & \multirow[t]{6}{*}{$\begin{array}{l}{ }^{18} \mathrm{~F}-\mathrm{FDG} \\
(\mathrm{STP})\end{array}$} & Chien et al. [2] & 2013 & 264 & $\begin{array}{l}83 \% \\
(75-89)\end{array}$ & $\begin{array}{l}91 \% \\
(86-95)\end{array}$ \\
\hline & & Wang et al. [3] & 2015 & 1330 & $\begin{array}{l}99 \% \\
(\mathrm{~N} / \mathrm{A})\end{array}$ & $\begin{array}{l}58 \% \\
(\mathrm{~N} / \mathrm{A})\end{array}$ \\
\hline & & Ruilong et al. [5] & 2017 & 1297 & $\begin{array}{l}82 \% \\
(76-87)\end{array}$ & $\begin{array}{l}81 \% \\
(66-90)\end{array}$ \\
\hline & & Li et al. [6] & 2018 & 1557 & $\begin{array}{l}89 \% \\
(87-91)\end{array}$ & $\begin{array}{l}70 \% \\
(66-73)\end{array}$ \\
\hline & & Divisi et al. [7] & 2018 & 1463 & $\begin{array}{l}82 \% \\
(79-84)\end{array}$ & $\begin{array}{l}62 \% \\
(58-66)\end{array}$ \\
\hline & & $\begin{array}{l}\text { Basso Dias et al. } \\
\text { [9] }\end{array}$ & 2019 & 4224 & $\begin{array}{l}78 \% \\
(70-84)\end{array}$ & $\begin{array}{l}81 \% \\
(72-88)\end{array}$ \\
\hline & \multirow{4}{*}{$\begin{array}{l}{ }^{18} \mathrm{~F}-\mathrm{FDG} \\
(\mathrm{DTP})\end{array}$} & Lin et al. [10] & 2012 & 788 & N/A & N/A \\
\hline & & Barger et al. [11] & 2012 & 816 & $\begin{array}{l}85 \% \\
(82-89)\end{array}$ & $\begin{array}{l}77 \% \\
(72-81)\end{array}$ \\
\hline & & Zhang et al. [12] & 2013 & 415 & $\begin{array}{l}79 \% \\
(74-84)\end{array}$ & $\begin{array}{l}73 \% \\
(65-79)\end{array}$ \\
\hline & & Zhao et al. [13] & 2016 & 962 & $\begin{array}{l}80 \% \\
(76-84)\end{array}$ & $\begin{array}{l}75 \% \\
(71-79)\end{array}$ \\
\hline & \multirow[t]{2}{*}{${ }^{18} \mathrm{~F}-\mathrm{FLT}$} & Li et al. [14] & 2015 & 301 & $\begin{array}{l}81 \% \\
(74-87)\end{array}$ & $\begin{array}{l}70 \% \\
(61-77)\end{array}$ \\
\hline & & Wang et al. [15] & 2015 & 351 & $\begin{array}{l}80 \% \\
(74-85)\end{array}$ & $\begin{array}{l}82 \% \\
(74-88)\end{array}$ \\
\hline
\end{tabular}


Considering the unsatisfactory results, especially in terms of specificity, the authors stated that ${ }^{18} \mathrm{~F}$ FDG PET/CT cannot replace the "gold standard" pathology by resection or biopsy.

Not dissimilar results have been reported in a further recent meta-analysis performed by Divisi and co-workers [7]. The authors concluded that despite ${ }^{18}$ F-FDG PET/CT presents a fairly good diagnostic accuracy in SPNs evaluation, it should not be considered as a discriminatory test rather than a method to be included in a clinical and diagnostic pathway.

Interestingly, Deppen and co-workers [8] evaluated the accuracy of ${ }^{18} \mathrm{~F}-\mathrm{FDG}$ PET in diagnosing lung cancer comparing populations with or without a risk for endemic infectious lung disease. They observed a $16 \%$ lower average adjusted specificity in regions with endemic infectious lung disease (61\%) compared with non-endemic regions (77\%). On the other hand, the sensitivity did not change appreciably by endemic infection status, even after adjusting for relevant factors. On the light of these results, the authors did not suggest the use of ${ }^{18}$ F-FDG PET to diagnose lung cancer in regions with endemic pulmonary infections unless an institution achieves test performance accuracy similar to that found in non-endemic regions.

Lastly, a meta-analysis investigates the diagnostic performance of ${ }^{18} \mathrm{~F}-\mathrm{FDG}$ PET/CT compared with diffusion-weighted magnetic resonance imaging (DW-MRI) for distinguishing malignant versus benign SPNs [9]. DW-MRI had a pooled sensitivity and specificity of $83 \%$ and $91 \%$, respectively, compared with $78 \%$ and $81 \%$, respectively, for PET/CT. The authors concluded that the diagnostic performance of DW-MRI is comparable or superior to that of ${ }^{18} \mathrm{~F}-\mathrm{FDG}$ PET/ $\mathrm{CT}$ in the differentiation of malignant and benign pulmonary lesions.

\subsubsection{Dual-Time-Point (DTP) PET}

Several authors have also explored the potential use of a DTP ${ }^{18} \mathrm{~F}$-FDG PET in differentiating malignant from benign SPNs (Table 5.1). In 2012, a meta-analysis was performed by Lin and co-workers [10] exploring the diagnostic performance of both single-time-point (STP) and DTP
${ }^{18}$ F-FDG PET techniques. Sensitivity was higher with DTP imaging at moderate levels of specificity. This potential advantage of DTP over initial STP scanning was diminished at higher levels of specificity. Although there was no clear evidence to support the routine use of DTP imaging with ${ }^{18} \mathrm{~F}-\mathrm{FDG}$ PET in the differential diagnosis of pulmonary nodules, the authors suggested as such technique may provide additional information in selected cases with equivocal results from initial scanning. Other meta-analyses [11-13] reported similar diagnostic accuracy among DTP and STP ${ }^{18} \mathrm{~F}$-FDG PET or PET/CT in the diagnosis of SPNs. According to these results, the additional value of DTP compared to STP ${ }^{18}$ F-FDG-PET/ $\mathrm{CT}$ resulted to be questionable.

\subsubsection{3 ${ }^{18}$ F-FLT PET for Evaluation of Pulmonary Lesions}

The potential use of fluorine-18 fluorothymidine $\left({ }^{18}\right.$ F-FLT) PET in patients with pulmonary lesions was evaluated by two meta-analyses $[14,15]$ (Table 5.1), which showed that ${ }^{18}$ F-FLT PET had a higher specificity but lower sensitivity compared to ${ }^{18} \mathrm{~F}$-FDG PET in the evaluation of SPNs. Therefore, the authors assumed that ${ }^{18} \mathrm{~F}-\mathrm{FLT}$ and ${ }^{18} \mathrm{~F}-\mathrm{FDG}$ together could add diagnostic confidence for pulmonary lesions.

\subsubsection{NSCLC Staging}

Nodal $(\mathrm{N})$ and distant metastases $(\mathrm{M})$ staging is one of the major prognostic factors of survival in NSCLC patients. Accurate staging of distant metastases is crucial, as the treatment strategy is directly dependent on tumour stage. Although many studies have been reported in the last decades evaluating the performance of ${ }^{18} \mathrm{~F}-\mathrm{FDG}$ $\mathrm{PET} / \mathrm{CT}$ in lung cancer staging, the results among studies are still almost controversial.

\subsubsection{N Staging}

Zhao and associates [16] performed a metaanalysis about ${ }^{18} \mathrm{~F}-\mathrm{FDG}$ PET/CT for detecting mediastinal nodal metastases in patients with NSCLC. The pooled sensitivity and specificity with $95 \%$ confidence interval values $(95 \% \mathrm{CI})$ on 
a per-patient analysis were $71.9 \%$ (95\%CI: 68.3$75.3 \%)$ and $89.8 \%$ (95\%CI: 88.2-91.2\%), respectively.

A second meta-analysis on the same issue [17] showed a pooled sensitivity of $62 \%$ for ${ }^{18} \mathrm{~F}-\mathrm{FDG}$ PET/CT (95\%CI: 54-70\%) and a pooled specificity of $92 \%$ (95\%CI: 88-95\%) on a node-based analysis. The pooled sensitivity and specificity were $67 \%$ (95\%CI: $54-79 \%$ ) and $87 \%$ (95\%CI: 82-91\%), respectively, on a patient-based analysis. Interestingly, those studies from tuberculosis endemic countries showed lower sensitivity and also lower specificity compared to nontuberculosis endemic countries [17, 18].

Two meta-analyses were specifically limited to early-stage NSCLC cases. In detail, Wang and co-workers [19] found that the negative predictive value (NPV) of ${ }^{18} \mathrm{~F}-\mathrm{FDG}$ PET/CT for lymph nodal mediastinal metastases was $94 \%$ for $\mathrm{T} 1$ disease and $89 \%$ for $\mathrm{T} 2$ disease. Including both $\mathrm{T} 1$ disease and $\mathrm{T} 2$ disease, the NPV was $93 \%$ for mediastinal metastases and $87 \%$ for overall nodal metastases. Interestingly, adenocarcinoma histology type and high ${ }^{18} \mathrm{~F}-\mathrm{FDG}$ uptake in the primary lesion were associated with greater risk of occult nodal metastases.

Similarly, a second meta-analysis [20] focused on patients with resectable NSCLC revealed that ${ }^{18}$ F-FDG PET/CT had a pooled sensitivity and specificity for N staging of $81.3 \%$ (95\%CI: $70.2-$ $88.9 \%$ ) and $79.4 \%$ (95\%CI: 70-86.5\%), respectively. The authors assumed that accuracy of ${ }^{18} \mathrm{~F}$-FDG PET/CT in N staging was insufficient to allow management and strategy of care based on ${ }^{18} \mathrm{~F}-\mathrm{FDG}$ PET/CT findings alone.

Shen et al. [21] also investigated the diagnostic value of DTP ${ }^{18} \mathrm{~F}-\mathrm{FDG}$ PET/CT versus STP imaging for detection of mediastinal nodal metastases in NSCLC patients. Pooled sensitivity and specificity for DTP PET/CT were $85 \%$ (95\% CI: $78-91 \%$ ) and 75\% (95\%CI: 68-82\%), respectively, and for STP imaging the same values were $79 \%(95 \% \mathrm{CI}: 70-85 \%)$ and $73 \%$ (95\%CI: 65-79\%), respectively. The authors were very cautious in supporting the implementation of DTP imaging in routine PET protocols for mediastinal lymph node staging of NSCLC.

Lastly, two meta-analyses compared ${ }^{18} \mathrm{~F}$-FDG PET/CT and DW-MRI for detection of mediasti- nal nodal metastases in NSCLC [22, 23] reporting similar results in terms of diagnostic accuracy among these two imaging methods.

\subsubsection{M Staging}

A meta-analysis by $\mathrm{Li}$ and co-workers [24] showed the excellent diagnostic performance of ${ }^{18} \mathrm{~F}-\mathrm{FDG}$ PET/CT for diagnosis of distant metastases in patients with NSCLC with a pooled sensitivity and specificity of 93\% (95\%CI: 88-96\%) and 96\% (95\%CI: 95-96), respectively. Similar results were reported by Yu et al. [25] who found a pooled sensitivity of $81 \%$ (95\%CI: 63-92\%) and 96\% (95\%CI: 94-98\%), respectively. A further meta-analysis on the same topic [26] demonstrated that concerning extra-thoracic metastases of NSCLC, the pooled sensitivities and specificities of ${ }^{18} \mathrm{~F}-\mathrm{FDG}$ PET/CT were $77 \%$ (95\% CI: 47-93\%) and 95\% (95\%CI: 92-97\%) for all extra-thoracic metastases, whereas the same values were 91\% (95\%CI: $80-97 \%$ ) and $98 \%$ (95\%CI: 94-99\%), respectively, for bone metastases. Conversely, ${ }^{18} \mathrm{~F}$-FDG PET/CT showed low sensitivity in detecting brain metastases.

Concerning the latter issue, a comparative meta-analysis MRI and ${ }^{18} \mathrm{~F}$-FDG PET/CT for the diagnosis of brain metastases in NSCLC [27] revealed that MRI had higher sensitivity (77\%) than ${ }^{18} \mathrm{~F}$-FDG PET/CT (21\%) for the diagnosis of brain metastases.

Chang et al. [28] found a higher sensitivity and specificity of ${ }^{18} \mathrm{~F}$-FDG PET/CT compared to bone scintigraphy (BS) in detecting bone metastases from NSCLC. A further more robust metaanalysis [29] showed that ${ }^{18} \mathrm{~F}-\mathrm{FDG}$ PET/CT is a better imaging method in terms of sensitivity and specificity compared to MRI and BS for detecting bone metastases from NSCLC, with a pooled sensitivity and specificity of $92 \%$ (95\%CI: 88-95\%) and 98\% (95\%CI: 97-98), respectively.

Finally, the diagnostic performance of ${ }^{18} \mathrm{~F}$ FDG PET/CT in detecting adrenal metastases from NSCLC was recently evaluated by $\mathrm{Wu}$ and co-workers [30]. The pooled sensitivity and specificity of ${ }^{18} \mathrm{~F}-\mathrm{FDG}$ PET/CT in this setting were $88.7 \%$ (95\%CI: 85.2-91.7\%) and 90.8\% (95\%CI: $87.5-93.4 \%)$, respectively, suggesting excellent performance. 


\subsubsection{Restaging After Induction Therapy and Prediction of Treatment Response}

The ability to identify potential responders to induction treatment may improve patient selection or surgery and may help in the development of response criteria suitable for routine monitoring of response. By providing information on the metabolic activity of tumour cells, ${ }^{18} \mathrm{~F}-\mathrm{FDG}$ PET/ $\mathrm{CT}$ has become a powerful tool in assessing treatment response. Zhang and colleagues [31] performed a meta-analysis to evaluate the value of ${ }^{18} \mathrm{~F}$-FDG PET in predicting the pathological tumour response of lung cancer to induction therapy. The authors found that ${ }^{18} \mathrm{~F}-\mathrm{FDG}$ PET could play an important role in predicting nonresponders to induction therapy in cases of lung cancer: indeed, the pooled sensitivity, specificity, positive predictive value, and negative predictive value for PET-predicted response were $83 \%$ (95\%CI: 76-89\%), 84\% (95\%CI: 79-88\%), 74\% (95\%CI: 67-81\%), and 91\% (95\%CI: 87-94\%), respectively.

A recent evidence-based article assessed the use of ${ }^{18} \mathrm{~F}-\mathrm{FDG}$ PET/CT for both assessing the efficacy of treatment response and performing post-treatment follow-up of lung cancer [32]. PET metabolic response (PERCIST criteria) has been shown to be a better predictor of histopathologic response than anatomic response metrics (WHO and RECIST criteria). ${ }^{18} \mathrm{~F}-\mathrm{FDG}$ PET/CT was indicated for treatment response assessment when it is performed within 6 months from treatment completion, though evidence for its comparative effectiveness with chest CT is still evolving.

\subsubsection{Radiation Therapy Pretreatment Planning in NSCLC}

${ }^{18}$ F-FDG PET/CT may also increase the likelihood of correctly delineating tumour tissue before radiotherapy dose planning. In 2017, Hallqvist and colleagues [33] reported the results of a meta-analysis on the use of ${ }^{18} \mathrm{~F}-\mathrm{FDG}$ PET/ $\mathrm{CT}$ for radiotherapy dose planning. According to this meta-analysis, a change in target definition was $36 \%$ in patients with a former staging PET, and $43 \%$ and $26 \%$ in patients without a staging PET for NSCLC and SCLC, respectively. The corresponding summary estimates of a change in treatment intent from curative to palliative treatment were $20 \%$ and $22 \%$ and $9 \%$, respectively. Another recent meta-analysis demonstrated that functional lung imaging, including PET, may have potential utility in radiation therapy planning and delivery [34].

\subsubsection{Diagnosis of Lung Cancer Recurrence}

Although there are no conclusive data to support the survival benefits of early detection or early treatment for recurrence of lung cancer, an early and accurate diagnosis of recurrence is critical to optimize therapy. A meta-analysis [35] was performed to assess the diagnostic value of ${ }^{18} \mathrm{~F}-\mathrm{FDG}$ PET and PET/CT for cases of recurrent lung cancer. In the patient-based analysis performed, ${ }^{18} \mathrm{~F}-$ FDG PET and PET/CT were found to provide better detection of lung cancer recurrence compared to CT. Indeed, the pooled sensitivity for ${ }^{18} \mathrm{~F}-\mathrm{FDG}$ PET, PET/CT, and CT were $94 \%$ (95\%CI: 91-97\%), 90\% (95\%CI: 84-95), and $78 \%$ (95\%CI: $71-84 \%$ ), respectively while the pooled specificity for ${ }^{18} \mathrm{~F}-\mathrm{FDG}$ PET, PET/CT, and CT were $84 \%$ (95\%CI: 77-89\%), 90\% (95\%CI: 87-93\%), and 80\% (95\%CI: 75-84\%), respectively.

\subsubsection{Prognostic Evaluation in NSCLC}

In their meta-analysis, Paesmans et al. [36] assessed the prognostic value of primary tumour maximum standardized uptake value (SUVmax) at ${ }^{18} \mathrm{~F}$-FDG PET for overall survival (OS) of NSCLC patients. At multivariate analysis, SUVmax was found to be independently associated with survival. The hazard ratio (HR) for SUVmax was 1.58 (95\%CI: 1.27-1.96).

Despite the SUVmax represents the most widely applied semi-quantitative PET parameter 
in clinical practice, volumetric PET parameters, including metabolic tumour volume (MTV) and total lesion glycolysis (TLG), have been also used to reflect disease burden and tumour aggressiveness in NSCLC. A first meta-analysis performed by Liu et al. [37] explored the prognostic value of SUVmax, MTV, and TLG on diseasefree survival (DFS) and OS in surgical NSCLC patients. The pooled HRs for OS were 1.52 for SUVmax, 1.91 for MTV, and 1.94 for TLG. On the basis of these results, the authors stated that high values of SUVmax, MTV, and TLG are able to predict a higher risk of recurrence or death in patients with surgical NSCLC, suggesting the use of ${ }^{18} \mathrm{~F}$-FDG PET/CT to select patients who are at high risk of disease recurrence or death as the best candidates from aggressive treatments. Other authors [38] conducted a meta-analysis on the prognostic value of MTV and TLG in NSCLC patients. A worse prognosis was observed in patients with high MTV (HR: 2.31) and with high TLG (HR: 2.43).

Han and colleagues [39] performed a metaanalysis exploring prognostic value of texture parameters derived by ${ }^{18} \mathrm{~F}$-FDG PET in patients with lung cancer. They concluded that there is insufficient evidence to support the prognostic value of texture analysis in ${ }^{18} \mathrm{~F}$-FDG PET in lung cancer.

Another interesting application of ${ }^{18} \mathrm{~F}-\mathrm{FDG}$ PET is the ability to predict long-term results after radiation therapy. Dong and co-workers [40] explored the prognostic relevance of SUVmax at ${ }^{18} \mathrm{~F}$-FDG PET for early-stage NSCLC patients receiving stereotactic body radiation therapy (SBRT). The authors found that those NSCLC patients presenting with high levels of pre-SBRT SUVmax had poorer OS and local control and higher risk of distant metastases. These findings were confirmed by another metaanalysis [41] showing that both pre-radiotherapy and post-radiotherapy primary tumour SUVmax can predict the outcome of patients with NSCLC treated with radiotherapy.

Other authors [42] have summarized the prognostic value of early response at ${ }^{18} \mathrm{~F}$-FDG PET in NSCLC patients treated with tyrosine-kinase inhibitors (TKI). Early response of patients with
NSCLC treated with TKIs identified on ${ }^{18} \mathrm{~F}-\mathrm{FDG}$ PET was found to be associated with improved OS and progression-free survival (PFS).

\subsubsection{Management of SCLC}

The role of ${ }^{18} \mathrm{~F}$-FDG PET in the management of SCLC has been largely investigated in the last decades. A systematic review and meta-analysis performed by Lu et al. [43] to evaluate the diagnostic accuracy of ${ }^{18} \mathrm{~F}-\mathrm{FDG}$ PET/CT in the pretherapeutic staging of patients with SCLC demonstrated a pooled sensitivity and specificity of $97.5 \%$ (95\%CI: 94.2-99.2\%) and $98.2 \%$ (95\%CI: 94.9-99.6\%), respectively, for the detection of extensive disease in SCLC patients. Therefore, evidence-based data suggest the role of ${ }^{18} \mathrm{~F}$-FDG PET/CT for discriminating between limited and extensive disease in SCLC.

The prognostic value of the SUVmax of primary SCLC at ${ }^{18} \mathrm{~F}$-FDG PET was recently investigated through a meta-analytic study [44]: the pooled HR for OS was 1.13 (95\%CI: 1.05-1.22), thus indicating that SCLC patients with high SUVmax may have poorer prognosis.

\subsection{Evidence-Based Data on PET in Pleural Tumours}

Three meta-analyses assessed the role of ${ }^{18} \mathrm{~F}$ FDG PET or PET/CT in the characterization of pleural lesions [45-47], whereas meta-analyses on the role of ${ }^{18} \mathrm{~F}$-FDG PET/CT in staging, restaging, prognostic or treatment response evaluation of pleural tumours are currently lacking.

${ }^{18}$ F-FDG-PET and PET/CT demonstrated to be accurate diagnostic imaging methods in the differential diagnosis between malignant and benign pleural lesions in patients with or without known cancer; nevertheless, possible sources of falsenegative and false-positive results should be kept in mind $[45,46]$. In patients without known cancer, sensitivity and specificity of ${ }^{18}$ F-FDG-PET and PET/CT were 95\% (95\%CI: 92-97\%) and 82\% (95\% CI: 76-88\%), respectively [45]. In patients with known cancer, pooled sensitivity 
was $86 \%$ (95\%CI: 80-91\%) and pooled specificity was $80 \%$ (95\%CI: 73-85\%) [46]. Porcel et al. in their meta-analysis [47] demonstrated that semi-quantitative PET assessment had a significantly lower sensitivity for diagnosing malignant pleural effusions than visual assessments. The pooled sensitivity and specificity of ${ }^{18} \mathrm{~F}-\mathrm{FDG}$ $\mathrm{PET} / \mathrm{CT}$ using semi-quantitative interpretation for identifying malignant pleural effusions were $81 \%$ and $74 \%$, respectively. The moderate accuracy of semi-quantitative PET assessment precludes its routine recommendation for discriminating malignant from benign pleural effusions.

\subsection{Evidence-Based Data on PET in Thymic Epithelial Tumours}

One meta-analysis [48] showed that ${ }^{18} \mathrm{~F}-\mathrm{FDG}$ PET may predict the WHO grade of malignancy in thymic epithelial tumours (TETs), reporting a statistically significant difference of SUVmax between the different TETs (low-grade thymomas, high-grade thymomas, and thymic carcinomas). In detail, the pooled mean difference of SUVmax between high-risk and low-risk thymomas was 1.2 (95\%CI: 0.4-2.0), that between thymic carcinomas and low-risk thymomas was 4.8 (95\% CI: 3.4-6.1), and that thymic carcinomas and high-risk thymomas was 3.5 (95\% CI: 2.7-4.3).

Notably, meta-analyses on the role of ${ }^{18} \mathrm{~F}-\mathrm{FDG}$ $\mathrm{PET} / \mathrm{CT}$ in staging, restaging, prognostic or treatment response evaluation of TETs are currently lacking.

\subsection{Evidence-Based Data on PET in Esophageal Tumours}

\subsubsection{Staging}

The real and unquestionable additional diagnostic value of ${ }^{18} \mathrm{~F}-\mathrm{FDG}$ PET/CT in comparison to conventional imaging methods is in evaluating distant metastases ( $\mathrm{M}$ staging) of esophageal cancer [49], whereas recent evidence-based articles have addressed the performance of ${ }^{18} \mathrm{~F}-\mathrm{FDG}$
PET/CT for detecting lymph nodal metastases ( $\mathrm{N}$ staging).

Jiang et al. [50] found that the pooled sensitivity and specificity estimates of ${ }^{18} \mathrm{~F}-\mathrm{FDG}$ PET/CT for detecting regional lymph nodal metastases at staging were $66 \%$ (95\% CI: $51-78 \%$ ) and $96 \%$ (95\% CI: 92-98\%), respectively. The corresponding values on a per-patient analysis were $65 \%$ (95\% CI: 49-78\%) and 81\% (95\%CI: 69-89\%), respectively. Overall, ${ }^{18} \mathrm{~F}-\mathrm{FDG}$ PET/CT has a moderate to low sensitivity and a high to moderate specificity for detection of regional nodal metastases in esophageal cancer. Therefore, extending the extent of lymph node dissection or radiotherapy target volume is necessary after the diagnosis of regional nodal metastases by ${ }^{18} \mathrm{~F}$ FDG PET/CT.

In another meta-analysis [51], Hu et al. evaluated the diagnostic performance of ${ }^{18} \mathrm{~F}-\mathrm{FDG}$ PET/ CT for the assessment of preoperative lymph node metastases in patients with esophageal cancer. In patients without neoadjuvant treatment, ${ }^{18} \mathrm{~F}-\mathrm{FDG}$ PET/CT had a pooled sensitivity and specificity of 57\% (95\%CI: 45-69\%) and 91\% (95\%CI: 85-95), respectively. In patients who received neoadjuvant treatment, ${ }^{18} \mathrm{~F}-\mathrm{FDG}$ PET/ CT had a pooled sensitivity and specificity of 53\% (95\%CI: 35-70\%) and 96\% (95\%CI: 86-99\%), respectively. Therefore, ${ }^{18} \mathrm{~F}-\mathrm{FDG}$ PET/CT has a high specificity but a low sensitivity; thus, it cannot accurately detect the lymph nodal involvement in patients with esophageal cancer.

Shi et al. [52] also demonstrated that ${ }^{18} \mathrm{~F}-\mathrm{FDG}$ PET/CT had lower sensitivity and accuracy for detection of regional nodal metastases in patients with esophageal cancer before surgery. The pooled sensitivity and specificity were $62 \%$ (95\%CI: 40-79\%) and 96\% (95\%CI: 93-98\%), respectively, on a per-station analysis; the corresponding values on a per-patient analysis were $55 \%$ (95\%CI: $34-74 \%)$ and $76 \%$ (95\% CI: 66-83\%), respectively.

In this setting, cervical ultrasonography has very limited additional diagnostic value as supplement to a negative ${ }^{18} \mathrm{~F}-\mathrm{FDG}$ PET/CT in the detection of cervical lymph node metastases during the initial staging of patients with esophageal cancer, as demonstrated by Goense et al. [53]. 


\subsubsection{Restaging}

Restaging after neoadjuvant therapy aims to reduce the number of patients undergoing oesophagectomy in case of distant (interval) metastases. Kroese et al. [54] assessed the diagnostic performance of ${ }^{18} \mathrm{~F}$-FDG PET or PET/CT for the detection of distant interval metastases after neoadjuvant therapy in patients with esophageal cancer. The pooled proportion of patients in whom true distant interval metastases were detected by ${ }^{18} \mathrm{~F}-\mathrm{FDG}$ PET or PET/CT at restaging was $8 \%$ (95\%CI: 5-13\%). The pooled proportion of patients in whom false-positive distant findings were detected by ${ }^{18} \mathrm{~F}-\mathrm{FDG}$ PET or PET/CT at restaging was 5\% (95\% CI: 3-9\%). In conclusion, ${ }^{18} \mathrm{~F}$-FDG PET or PET/CT at restaging after neoadjuvant therapy for esophageal cancer can considerably impact on treatment decisionmaking. However, pathological confirmation of suspected lesions is needed.

Cong et al. [55] assessed the value of ${ }^{18} \mathrm{~F}$ FDG PET or PET/CT for response prediction of primary tumour in patients with esophageal cancer during (group A) or after (group B) neoadjuvant chemoradiotherapy. The pooled sensitivity and specificity were $85 \% \quad(95 \% \mathrm{CI}$ : 76-91\%) and 59\% (95\% CI: 48-69\%), respectively, in group A. The equivalent values were $67 \%$ (95\% CI: $60-73 \%$ ) and 69\% (95\% CI: $63-74 \%)$, respectively, in group B. Interestingly, the pooled sensitivity was $90 \%$ in the studies that enrolled patients with esophageal squamous cell carcinoma merely in group B. According to the present data, ${ }^{18} \mathrm{~F}-\mathrm{FDG}$ PET/ CT should not be used routinely to guide treatment strategy in esophageal cancer patients, but an additional value is expected in patients with esophageal squamous cell carcinoma treated with neoadjuvant chemoradiotherapy.

Goense et al. [56] assessed the diagnostic performance of ${ }^{18} \mathrm{~F}$-FDG PET or PET/CT for diagnosing recurrent esophageal cancer after initial treatment with curative intent. Pooled estimates of sensitivity and specificity for ${ }^{18} \mathrm{~F}$-FDG PET and PET/CT in this setting were $96 \%$ (95\%CI: 93-97\%) and 78\% (95\% CI: 66-86\%), respec- tively. Therefore, ${ }^{18} \mathrm{~F}$-FDG PET and PET/CT are reliable imaging modalities with a high sensitivity and moderate specificity for detecting recurrent esophageal cancer after treatment with curative intent. However, histopathologic confirmation of PET/CT-suspected lesions is required, because a considerable false-positive rate is noticed.

\subsubsection{Predictive and Prognostic Value}

Han et al. [57] performed a meta-analysis on the prognostic value of volumetric parameters (MTV and TLG) derived from pretreatment ${ }^{18} \mathrm{~F}-\mathrm{FDG}$ $\mathrm{PET} / \mathrm{CT}$ in patients with esophageal cancer. The pooled HRs of MTV and TLG for OS were 2.26 (95\%CI: 1.73-2.96) and 2.23 (95\%CI: 1.732.87), respectively. Regarding event-free survival, the pooled HRs of MTV and TLG were 2.03 (95\%CI: 1.66-2.49) and 2.57 (95\% CI: 1.82-3.62), respectively. Therefore, in patients with esophageal cancer, MTV and TLG derived from pretreatment ${ }^{18} \mathrm{~F}$-FDG PET are significant prognostic factors.

Schollaert et al. [58] performed a metaanalysis on the predictive value of ${ }^{18} \mathrm{~F}$-FDG PET for assessing DFS and OS in esophageal and oesophagogastric junction cancer after neoadjuvant chemoradiation therapy. The pooled HRs for complete metabolic response versus no response were 0.51 for OS (95\%CI: $0.4-0.64$ ) and 0.47 for DFS (95\%CI: 0.38-0.57), respectively. Therefore, metabolic response on ${ }^{18} \mathrm{~F}$-FDG PET is a significant predictor of long-term survival.

Lastly, Zhu et al. [59] performed a metaanalysis on the prognostic significance of SUVmax on ${ }^{18} \mathrm{~F}$-FDG PET/CT in patients with localized oesophagogastric junction cancer receiving neoadjuvant chemotherapy/chemoradiation therapy. Significant prognostic values of SUVmax before and during therapy in localized oesophagogastric junction cancer were not found. Conversely, relative changes in ${ }^{18}$ F-FDG-uptake after therapy are significant prognostic markers for OS and DFS. 


\section{References}

1. MacMahon H, Naidich DP, Goo JM, Lee KS, Leung ANC, Mayo JR, et al. Guidelines for management of incidental pulmonary nodules detected on CT images: from the Fleischner Society 2017. Radiology. 2017;284(1):228-43.

2. Chien CR, Liang JA, Chen JH, Wang HN, Lin CC, Chen CY, et al. [(18)F]Fluorodeoxyglucose-positron emission tomography screening for lung cancer: a systematic review and meta-analysis. Cancer Imaging. 2013;13(4):458-65.

3. Wang HQ, Zhao L, Zhao J, Wang Q. Analysis on early detection of lung cancer by PET/CT scan. Asian Pac J Cancer Prev. 2015;16(6):2215-7.

4. Madsen PH, Holdgaard PC, Christensen JB, HøilundCarlsen PF. Clinical utility of F-18 FDG PET-CT in the initial evaluation of lung cancer. Eur J Nucl Med Mol Imaging. 2016;43(11):2084-97.

5. Ruilong Z, Daohai X, Li G, Xiaohong W, Chunjie W, Lei T. Diagnostic value of 18F-FDG-PET/CT for the evaluation of solitary pulmonary nodules: a systematic review and meta-analysis. Nucl Med Commun. 2017;38(1):67-75.

6. Li ZZ, Huang YL, Song HJ, Wang YJ, Huang Y. The value of 18F-FDG-PET/CT in the diagnosis of solitary pulmonary nodules: a meta-analysis. Medicine. 2018;97(12):e0130.

7. Divisi D, Barone M, Bertolaccini L, Zaccagna G, Gabriele F, Crisci R. Diagnostic performance of fluorine-18 fluorodeoxyglucose positron emission tomography in the management of solitary pulmonary nodule: a meta-analysis. J Thorac Dis. 2018;10(Suppl 7):S779-89.

8. Deppen SA, Blume JD, Kensinger CD, Morgan AM, Aldrich MC, Massion PP, et al. Accuracy of FDG-PET to diagnose lung cancer in areas with infectious lung disease: a meta-analysis. JAMA. 2014;312(12):1227-36.

9. Basso Dias A, Zanon M, Altmayer S, Sartori Pacini G, Henz Concatto N, Watte G, et al. Fluorine 18-FDG PET/CT and diffusion-weighted MRI for malignant versus benign pulmonary lesions: a Meta-analysis. Radiology. 2019;290(2):525-34.

10. Lin YY, Chen JH, Ding HJ, Liang JA, Yeh JJ, Kao $\mathrm{CH}$. Potential value of dual-time-point ${ }^{18} \mathrm{~F}-\mathrm{FDG}$ PET compared with initial single-time-point imaging in differentiating malignant from benign pulmonary nodules: a systematic review and meta-analysis. Nucl Med Commun. 2012;33(10):1011-8.

11. Barger RL Jr, Nandalur KR. Diagnostic performance of dual-time 18F-FDG PET in the diagnosis of pulmonary nodules: a meta-analysis. Acad Radiol. 2012;19(2):153-8.

12. Zhang L, Wang Y, Lei J, Tian J, Zhai Y. Dual time point 18FDG-PET/CT versus single time point 18FDG-PET/CT for the differential diagnosis of pulmonary nodules: a meta-analysis. Acta Radiol. 2013;54(7):770-7.
13. Zhao M, Ma Y, Yang B, Wang Y. A meta-analysis to evaluate the diagnostic value of dual-time-point F-fluorodeoxyglucose positron emission tomography/ computed tomography for diagnosis of pulmonary nodules. J Cancer Res Ther. 2016;12(Suppl):C304-8.

14. Li XF, Dai D, Song XY, Liu JJ, Zhu YJ, Xu WG. Comparison of the diagnostic performance of $18 \mathrm{~F}$-fluorothymidine versus $18 \mathrm{~F}$-fluorodeoxyglucose positron emission tomography on pulmonary lesions: a meta analysis. Mol Clin Oncol. 2015;3(1):101-8.

15. Wang Z, Wang Y, Sui X, Zhang W, Shi R, Zhang Y, et al. Performance of FLT-PET for pulmonary lesion diagnosis compared with traditional FDG-PET: a meta-analysis. Eur J Radiol. 2015;84(7):1371-7.

16. Zhao L, He ZY, Zhong XN, Cui ML. (18)FDG-PET/ CT for detection of mediastinal nodal metastasis in non-small cell lung cancer: a meta-analysis. Surg Oncol. 2012;21(3):230-6.

17. Pak K, Park S, Cheon GJ, Kang KW, Kim IJ, Lee DS, et al. Update on nodal staging in non-small cell lung cancer with integrated positron emission tomography/ computed tomography: a meta-analysis. Ann Nucl Med. 2015;29(5):409-19.

18. Liao CY, Chen JH, Liang JA, Yeh JJ, Kao CH. Metaanalysis study of lymph node staging by 18 F-FDG PET/CT scan in non-small cell lung cancer: comparison of TB and non-TB endemic regions. Eur J Radiol. 2012;81(11):3518-23.

19. Wang J, Welch K, Wang L, Kong FM. Negative predictive value of positron emission tomography and computed tomography for stage T1-2N0 non-smallcell lung cancer: a meta-analysis. Clin Lung Cancer. 2012;13(2):81-9.

20. Schmidt-Hansen M, Baldwin DR, Hasler E, Zamora J, Abraira V, Roqué I Figuls M. PET-CT for assessing mediastinal lymph node involvement in patients with suspected resectable non-small cell lung cancer. Cochrane Database Syst Rev. 2014;(11):CD009519.

21. Shen G, Hu S, Deng H, Jia Z. Diagnostic value of dual time-point 18 F-FDG PET/CT versus single time-point imaging for detection of mediastinal nodal metastasis in non-small cell lung cancer patients: a meta-analysis. Acta Radiol. 2015;56(6):681-7.

22. Wu LM, Xu JR, Gu HY, Hua J, Chen J, Zhang W, et al. Preoperative mediastinal and hilar nodal staging with diffusion-weighted magnetic resonance imaging and fluorodeoxyglucose positron emission tomography/computed tomography in patients with nonsmall-cell lung cancer: which is better? J Surg Res. 2012;178(1):304-14.

23. Shen G, Lan Y, Zhang K, Ren P, Jia Z. Comparison of 18F-FDG PET/CT and DWI for detection of mediastinal nodal metastasis in non-small cell lung cancer: a meta-analysis. PLoS One. 2017;12(3):e0173104.

24. Li J, Xu W, Kong F, Sun X, Zuo X. Meta-analysis: accuracy of 18FDG PET-CT for distant metastasis staging in lung cancer patients. Surg Oncol. 2013;22(3):151-5.

25. Yu B, Zhu X, Liang Z, Sun Y, Zhao W, Chen K. Clinical usefulness of 18F-FDG PET/CT for 
the detection of distant metastases in patients with non-small cell lung cancer at initial staging: a metaanalysis. Cancer Manag Res. 2018;10:1859-64.

26. Wu Y, Li P, Zhang H, Shi Y, Wu H, Zhang J, et al. Diagnostic value of fluorine 18 fluorodeoxyglucose positron emission tomography/computed tomography for the detection of metastases in non-small-cell lung cancer patients. Int J Cancer. 2013;132(2):E37-47.

27. Li Y, Jin G, Su D. Comparison of gadoliniumenhanced MRI and 18FDG PET/PET-CT for the diagnosis of brain metastases in lung cancer patients: a meta-analysis of 5 prospective studies. Oncotarget. 2017;8(22):35743-9.

28. Chang MC, Chen JH, Liang JA, Lin CC, Yang KT, Cheng KY, et al. Meta-analysis: comparison of F-18 fluorodeoxyglucose-positron emission tomography and bone scintigraphy in the detection of bone metastasis in patients with lung cancer. Acad Radiol. 2012;19(3):349-57.

29. Qu X, Huang X, Yan W, Wu L, Dai K. A meta-analysis of ${ }^{18}$ FDG-PET-CT, ${ }^{18}$ FDG-PET, MRI and bone scintigraphy for diagnosis of bone metastases in patients with lung cancer. Eur J Radiol. 2012;81(5):1007-15.

30. Wu Q, Luo W, Zhao Y, Xu F, Zhou Q. The utility of 18F-FDG PET/CT for the diagnosis of adrenal metastasis in lung cancer: a PRISMA-compliant metaanalysis. Nucl Med Commun. 2017;38(12):1117-24.

31. Zhang C, Liu J, Tong J, Sun X, Song S, Huang G. 18F-FDG-PET evaluation of pathological tumour response to neoadjuvant therapy in patients with NSCLC. Nucl Med Commun. 2013;34(1):71-7.

32. Sheikhbahaei S, Mena E, Yanamadala A, Reddy S, Solnes LB, Wachsmann J, et al. The value of FDG $\mathrm{PET} / \mathrm{CT}$ in treatment response assessment, followup, and surveillance of lung cancer. AJR Am J Roentgenol. 2017;208(2):420-33.

33. Hallqvist A, Alverbratt C, Strandell A, Samuelsson O, Björkander E, Liljegren A, et al. Positron emission tomography and computed tomographic imaging (PET/CT) for dose planning purposes of thoracic radiation with curative intent in lung cancer patients: a systematic review and meta-analysis. Radiother Oncol. 2017;123(1):71-7.

34. Bucknell NW, Hardcastle N, Bressel M, Hofman MS, Kron T, Ball D, et al. Functional lung imaging in radiation therapy for lung cancer: a systematic review and meta-analysis. Radiother Oncol. 2018;129(2):196-208.

35. He YQ, Gong HL, Deng YF, Li WM. Diagnostic efficacy of PET and PET/CT for recurrent lung cancer: a meta-analysis. Acta Radiol. 2014;55(3):309-17.

36. Paesmans M, Garcia C, Wong CY, Patz EF Jr, Komaki $\mathrm{R}$, Eschmann S, et al. Primary tumour standardised uptake value is prognostic in nonsmall cell lung cancer: a multivariate pooled analysis of individual data. Eur Respir J. 2015;46(6):1751-61.

37. Liu J, Dong M, Sun X, Li W, Xing L, Yu J. Prognostic value of $18 \mathrm{~F}-\mathrm{FDG}$ PET/CT in surgical non-small cell lung cancer: a Meta-analysis. PLoS One. 2016;11(1):e0146195.
38. Im HJ, Pak K, Cheon GJ, Kang KW, Kim SJ, Kim IJ, et al. Prognostic value of volumetric parameters of (18)F-FDG PET in non-small-cell lung cancer: a meta-analysis. Eur J Nucl Med Mol Imaging. 2015;42(2):241-51.

39. Han S, Woo S, Suh CH, Kim YJ, Oh JS, Lee JJ. A systematic review of the prognostic value of texture analysis in 18F-FDG PET in lung cancer. Ann Nucl Med. 2018;32(9):602-10.

40. Dong M, Liu J, Sun X, Xing L. Prognositc significance of SUVmax on pretreatment 18 F-FDG PET/ $\mathrm{CT}$ in early-stage non-small cell lung cancer treated with stereotactic body radiotherapy: a meta-analysis. Acta Radiol. 2018;59(9):1082-90.

41. Na F, Wang J, Li C, Deng L, Xue J, Lu Y. Primary tumor standardized uptake value measured on F18Fluorodeoxyglucose positron emission tomography is of prediction value for survival and local control in non-small-cell lung cancer receiving radiotherapy: meta-analysis. $\mathrm{J}$ Thorac Oncol. 2014;9(6):834-42.

42. Ma J, Wu X, Li J, Wang Z, Wang Y. Prognostic value of early response assessment using (18F)FDG-PET in patients with advanced non-small cell lung cancer treated with tyrosine-kinase inhibitors. J Investig Med. 2017;65(5):935-41.

43. Lu YY, Chen JH, Liang JA, Chu S, Lin WY, Kao CH. 18F-FDG PET or PET/CT for detecting extensive disease in small-cell lung cancer: a systematic review and meta-analysis. Nucl Med Commun. 2014;35(7):697-703.

44. Zhu D, Wang Y, Wang L, Chen J, Byanju S, Zhang $\mathrm{H}$, et al. Prognostic value of the maximum standardized uptake value of pre-treatment primary lesions in small-cell lung cancer on 18F-FDG PET/CT: a metaanalysis. Acta Radiol. 2018;59(9):1082-90.

45. Treglia G, Sadeghi R, Annunziata S, Lococo F, Cafarotti S, Bertagna F, et al. Diagnostic accuracy of 18F-FDG-PET and PET/CT in the differential diagnosis between malignant and benign pleural lesions: a systematic review and meta-analysis. Acad Radiol. 2014;21(1):11-20.

46. Treglia G, Sadeghi R, Annunziata S, Lococo F, Cafarotti S, Prior JO, et al. Diagnostic performance of fluorine-18-fluorodeoxyglucose positron emission tomography in the assessment of pleural abnormalities in cancer patients: a systematic review and a meta-analysis. Lung Cancer. 2014;83(1):1-7.

47. Porcel JM, Hernández P, Martínez-Alonso M, Bielsa S, Salud A. Accuracy of fluorodeoxyglucose-PET imaging for differentiating benign from malignant pleural effusions: a meta-analysis. Chest. 2015;147(2):502-12.

48. Treglia G, Sadeghi R, Giovanella L, Cafarotti S, Filosso P, Lococo F. Is (18)F-FDG PET useful in predicting the WHO grade of malignancy in thymic epithelial tumors? A meta-analysis. Lung Cancer. 2014;86(1):5-13.

49. Marzola MC, De Manzoni G, Grassetto G, Cordiano C, Al-Nahhas A, Alavi A, et al. Extended staging 
of oesophageal cancer using FDG-PET - a critical appraisal. Eur J Radiol. 2012;81(1):21-30.

50. Jiang C, Chen Y, Zhu Y, Xu Y. Systematic review and meta-analysis of the accuracy of 18F-FDG PET/CT for detection of regional lymph node metastasis in esophageal squamous cell carcinoma. J Thorac Dis. 2018;10(11):6066-76.

51. Hu J, Zhu D, Yang Y. Diagnostic value of 18F-fluorodeoxyglucose positron-emission tomography/computed tomography for preoperative lymph node metastasis of esophageal cancer: a metaanalysis. Medicine. 2018;97(50):e13722.

52. Shi W, Wang W, Wang J, Cheng H, Huo X. Metaanalysis of 18FDG PET-CT for nodal staging in patients with esophageal cancer. Surg Oncol. 2013;22(2):112-6.

53. Goense L, Meziani J, van Rossum PSN, Wessels FJ, Meijer GJ, Lam MGEH, et al. Limited additional value of cervical ultrasonography over a negative 18F-FDG PET/CT for diagnosing cervical lymph node metastases in patients with esophageal cancer: a systematic review and meta-analysis. Nucl Med Commun. 2018;39(7):645-51.

54. Kroese TE, Goense L, van Hillegersberg R, de Keizer B, Mook S, Ruurda JP, et al. Detection of distant interval metastases after neoadjuvant therapy for esophageal cancer with $18 \mathrm{~F}-\mathrm{FDG}$ PET(/CT): a systematic review and meta-analysis. Dis Esophagus. 2018;31(12).
55. Cong L, Wang S, Gao T, Hu L. The predictive value of 18F-FDG PET for pathological response of primary tumor in patients with esophageal cancer during or after neoadjuvant chemoradiotherapy: a metaanalysis. Jpn J Clin Oncol. 2016;46(12):1118-26.

56. Goense L, van Rossum PS, Reitsma JB, Lam MG, Meijer GJ, van Vulpen M, et al. Diagnostic performance of ${ }^{18} \mathrm{~F}$-FDG PET and PET/CT for the detection of recurrent esophageal cancer after treatment with curative intent: a systematic review and metaanalysis. J Nucl Med. 2015;56(7):995-1002.

57. Han S, Kim YJ, Woo S, Suh CH, Lee JJ. Prognostic value of volumetric parameters of pretreatment 18F-FDG PET/CT in esophageal cancer: a systematic review and meta-analysis. Clin Nucl Med. 2018;43(12):887-94.

58. Schollaert P, Crott R, Bertrand C, D'Hondt L, Borght TV, Krug B. A systematic review of the predictive value of (18)FDG-PET in esophageal and esophagogastric junction cancer after neoadjuvant chemoradiation on the survival outcome stratification. J Gastrointest Surg. 2014;18(5):894-905.

59. Zhu W, Xing L, Yue J, Sun X, Sun X, Zhao $\mathrm{H}$, et al. Prognostic significance of SUV on PET/CT in patients with localised oesophagogastric junction cancer receiving neoadjuvant chemotherapy/chemoradiation:a systematic review and meta-analysis. Br J Radiol. 2012;85(1017):e694-701.

Open Access This chapter is licensed under the terms of the Creative Commons Attribution 4.0 International License (http://creativecommons.org/licenses/by/4.0/), which permits use, sharing, adaptation, distribution and reproduction in any medium or format, as long as you give appropriate credit to the original author(s) and the source, provide a link to the Creative Commons license and indicate if changes were made.

The images or other third party material in this chapter are included in the chapter's Creative Commons license, unless indicated otherwise in a credit line to the material. If material is not included in the chapter's Creative Commons license and your intended use is not permitted by statutory regulation or exceeds the permitted use, you will need to obtain permission directly from the copyright holder. 